\title{
Commentary: Advancement of knowledge of Brucella over the past 50 years
}

\author{
Giovanni Di Guardo ${ }^{1 *}$ and Sandro Mazzariol ${ }^{2}$ \\ ${ }^{1}$ Faculty of Veterinary Medicine, University of Teramo, Teramo, Italy, ${ }^{2}$ Department of Comparative Biomedicine and Food \\ Science, University of Padova, Legnaro, Italy
}

Keywords: Brucella ceti, cellular prion protein, persistent organic pollutants, dioxin, dioxin-like substances, striped dolphin, Stenella coeruleoalba

\section{A commentary on}

Advancement of knowledge of Brucella over the past 50 years

by Olsen SC, Palmer MV. Vet Pathol (2014) 51:1076-1089. doi: 10.1177/0300985814540545

Brucella ceti, a cetacean and zoonotic pathogen displaying a marked neurotropism in striped dolphins (Stenella coeruleoalba), appears to be the ancestor and a close relative of B. abortus, infecting cattle, as well as of $B$. melitensis, infecting sheep and goat (1).

In addition to the elegant mechanisms and strategies utilized by Brucella genus members for entering and surviving into host cells, which are clearly explained in the aforementioned review article (2), the interaction between bacterial Hsp60 - a member of the GroEL family of chaperonins and cellular prion protein $\left(\mathrm{PrP}^{\mathrm{C}}\right)$ has been reported to play a crucial role in $B$. abortus infection of murine, bone marrow-derived macrophages, with no evidence of microbial colonization and replication in cells from $\operatorname{PrP}^{\mathrm{C}}$-deficient mice $(3,4)$.

As "top predators," cetaceans may accumulate within their tissues high concentrations of immunotoxic and neurotoxic "persistent organic pollutants" (POPs) like dioxins and dioxin-like compounds (DLCs) $(5,6)$, which have been demonstrated to exert pro-apoptotic activity on human neuronal cells (7). As a consequence, following dioxin-induced apoptosis, $\operatorname{PrP}^{\mathrm{C}}$ overexpression is likely to occur on host cell membrane, given the anti-apoptotic role of $\mathrm{PrP}^{\mathrm{C}}$, which is consistently expressed on brain cells (8).

Based upon the aforementioned model, the heavy (cerebral and extra-neural) tissue loads of lipophylic dioxins and DLCs commonly detected in stranded dolphins $(5,6)$ could elicit $\operatorname{PrP}^{\mathrm{C}}$ overexpression on behalf of brain cells, resulting at its turn in an amplified colonization and replication activity of $B$. cet $i$ inside these cells. The recently characterized expression patterns of $\operatorname{PrP}^{C}$ within the cerebral parenchyma as well as in secondary lymphoid tissues from wild dolphins (9), which resemble those previously reported in terrestrial mammals (8), provide additional support for such hypothesis, thereby making biologically plausible the occurrence of "neurobrucellosis," a neurological disease condition frequently observed in B. ceti-affected striped dolphins (1). Indeed, high levels of dioxins and DLCs have been recently found in tissues from $B$. ceti meningoencephalitisaffected striped dolphins beached along the Ionian Sea coast of Italy (Antonio Petrella and Pasquale Troiano, personal communication).

In this respect, it should be also emphasized that significant differences have been recently reported in the endo-cerebral expression levels of 5-lipoxygenase (5-LOX), a neurodegeneration biomarker (10), between infectious encephalitis/meningoencephalitis-affected and -unaffected striped dolphins, with the most consistent intensity of expression of the aforementioned enzyme having been detected in a $B$. ceti-infected individual (11). This appears to be a remarkable 
finding, provided that such an extensive neuroinflammatory and neurodegenerative lesions' pattern could have acted synergistically with the high tissue concentrations of dioxins and DLCs found in this dolphin (Antonio Petrella and Pasquale Troiano, personal communication), thereby leading to $\mathrm{PrP}^{\mathrm{C}}$ overexpression, with subsequent putative increase of $B$. ceti colonization and replication inside brain cells.

In conclusion, based upon the strong impact exerted by $B$. cet $i$ infection on the health and conservation status of free-ranging cetaceans all across the globe, associated with the proven zoonotic capability of this microorganism $(1,5,12)$, the study of the infection's neuropathogenesis, including the strategies adopted by $B$. cet $i$ in crossing the blood-brain barrier from striped dolphins,

\section{References}

1. Guzmán-Verri C, González-Barrientos R, Hernández-Mora G, Morales JA, Baquero-Calvo E, Chaves-Olarte E, et al. Brucella ceti and brucellosis in cetaceans. Front Cell Infect Microbiol (2012) 2:3. doi: $10.3389 /$ fcimb. 2012.00003

2. Olsen SC, Palmer MV. Advancement of knowledge of Brucella over the past 50 years. Vet Pathol (2014) 51:1076-89. doi:10.1177/0300985814540545

3. Aguzzi A, Hardt W-D. Dangerous liaisons between a microbe and the prion protein. J Exp Med (2003) 198:1-4. doi:10.1084/jem.20030732

4. Watarai M, Kim S, Erdenebaatar J, Makino S, Horiuchi M, Shirahata T, et al Cellular prion protein promotes Brucella infection into macrophages. J Exp Med (2003) 198:5-17. doi:10.1084/jem.20021980

5. Van Bressem M-F, Raga J-A, Di Guardo G, Jepson PD, Duignan PJ, Siebert U, et al. Emerging infectious diseases in cetaceans worldwide and the possible role of environmental stressors. Dis Aquat Organ (2009) 86:143-57. doi:10.3354/ dao02101

6. Fossi MC, Casini S, Maltese S, Panti C, Spinsanti G, Marsili L. An "ex vivo" model to evaluate toxicological responses to mixtures of contaminants in cetaceans: integumentum biopsy slices. Environ Toxicol (2014) 29:1107-21. doi:10.1002/tox.21841

7. Morales-Hernández A, Sánchez-Martín FJ, Hortigón-Vinagre MP, Henao F, Merino JM. 2,3,7,8 Tetrachlorodibenzo-p-dioxin induces apoptosis by disruption of intracellular calcium homeostasis in human neuronal cell line SHSY5Y. Apoptosis (2012) 17:1170-81. doi:10.1007/s10495-012-0760-z

8. Aguzzi A, Sigurdson C, Heikenwalder M. Molecular mechanisms of prion pathogenesis. Annu Rev Pathol (2008) 3:11-40. doi:10.1146/annurev. pathmechdis.3.121806.154326 would deserve adequate attention. Particular emphasis should be additionally placed on the study of the infection's epidemiology and of the evolutionary genetics of $B$. ceti, also in comparison with all the other known Brucella genus members, as well as on the study of host-pathogen interaction dynamics, with special reference to the "host related" $\left(\mathrm{PrP}^{\mathrm{C}}\right.$ expression levels and patterns) and to the "environment related" (POPs, dioxins, DLCs, etc.) drivers and modulators of such complex interplay.

\section{Acknowledgments}

We wish to thank Prof. Adriano Aguzzi for his critical reading and his valuable comments on the manuscript.

9. Di Guardo G, Cocumelli C, Meoli R, Barbaro K, Terracciano G, Di Francesco $\mathrm{CE}$, et al. Prion search and cellular prion protein expression in stranded dolphins. J Biol Regul Homeost Agents (2012) 26:567-70.

10. Chu J, Giannopoulos PF, Ceballos-Diaz C, Golde TE, Pratico D. Adenoassociated virus mediated brain delivery of 5-lipoxygenase modulates the AD-like phenotype of APP mice. Mol Neurodegener (2012) 7:1. doi:10.1186/ 1750-1326-7-1

11. Di Guardo G, Falconi A, Di Francesco A, Mazzariol S, Centelleghe C, Casalone $\mathrm{C}$, et al. Western blot expression of 5-lipoxygenase in the brain from striped dolphins (Stenella coeruleoalba) and bottlenose dolphins (Tursiops truncatus) with or without encephalitis/meningo-encephalitis of infectious nature. J Biol Regul Homeost Agents (2015) 29:245-50.

12. Di Guardo G, Mazzariol S, Fernández A. Biologically threatened dolphins and whales. Environ Microbiol (2011) 13:2833-4. doi:10.1111/j.1462-2920.2011. 02565.x

Conflict of Interest Statement: The Review Editor Antonio Frangipane Di Regalbono declares that, despite being affiliated to the same institution as author Sandro Mazzariol, the review process was handled objectively and no conflict of interest exists. The authors declare that the research was conducted in the absence of any commercial or financial relationships that could be construed as a potential conflict of interest.

Copyright (C) 2015 Di Guardo and Mazzariol. This is an open-access article distributed under the terms of the Creative Commons Attribution License (CC BY). The use, distribution or reproduction in other forums is permitted, provided the original author(s) or licensor are credited and that the original publication in this journal is cited, in accordance with accepted academic practice. No use, distribution or reproduction is permitted which does not comply with these terms. 